\title{
СОЗДАНИЕ ЛИНГВОДИДАКТИЧЕСКОЙ МУЛЬТИМЕДИЙНОЙ СРЕДЫ ОБУЧЕНИЯ ИНОЯЗЫЧНОМУ РЕЧЕВОМУ ОБЩЕНИЮ
}

\section{CREATING LINGUODIDACTIC MULTIMEDIA ENVIRONMENT FOR FOREIGN LANGUAGE SPEECH COMMUNICATION TEACHING}

E. Burina

Summary: The article provides an insight into the problem of creating linguodidactic environment for foreign speech communication teaching under new information conditions, which would reflect features of the real language environment and contribute to its linguodidactic functions' implementation. The environment surrounding the learning subject should represent the necessary didactic environment with a view to achieving targeted objectives as well as create interaction and mutual influence relationship with the subject of learning for the teacher and the student to use all available opportunities of it. We consider material realities from the language metropolis country; audio-visual series; situational speech series and text to be the main components of the linguistic and didactic environment. Teaching speech communication in the era of global informatization of society is implemented with the help of such particular didactic principles as: intercultural interaction, oral anticipation, functionality, communicativeness, variability, didactic integration, interactivity, open environment, ICT application relevance. The author determines artificial linguistic environment' multimedia components of teaching a foreign language and suggests its methodical adaptation ways.

Keywords: linguodidactic environment, real environment, artificial environment, ICT, teaching principles, foreign language, learning process, text, language environment.
И нформационно-коммуникативные технологии занимают все большее место во всех сферах жизни общества, включая образование. Они способствуют появлению и развитию новых образовательных систем, которые основываются на личностно-ориентированном проблемном обучении и направлены на активизацию самостоятельной учебной и познавательной деятельности учащихся. ИКТ могут осуществить свой образовательный потенциал в специально организованных информационных лингводидактических средах для обучения иностранному языку.

Таким образом, основной методической задачей является создание лингводидактической среды, которая отражала бы специфику реальной языковой среды и способствовала бы осуществлению ее лингводидактических функций.
Бурина Елена Владимировна

К.п.н., дочент, Московский государственный институт международных отношений (университет) helenabourina@yandex.ru

Аннотация: Статья посвящена проблеме создания лингводидактической среды обучения иноязычному речевому общению в новых информационных условиях, которая отражала бы специфику реальной языковой среды и способствовала бы осуществлению ее лингводидактических функций. Среда, окружающая субъект обучения, должна представлять собой необходимое дидактическое окружение с целью достижения намеченных целей и находиться с субъектом обучения в отношениях взаимодействия и взаимовлияния для использования преподавателем и учащимся всех доступных в ней возможностей. Основными компонентами лингводидактической языковой среды мы рассматриваем материальные реалии из страны языковой метрополии; аудиовизуальный ряд; речевой ситуативный ряд; текст. Обучение речевому общению в эпоху всемирной информатизации общества реализуется с помощью таких частнодидактических принципов, как: межкультурного взаимодействия, устного опережения, функциональности, коммуникативности, вариативности, дидактической интегрированности, интерактивности, открытости среды, целесообразности применения ИКТ. Определены мультимедийные компоненты искусственной языковой среды в обучении иностранному языку и предложены пути их методической адаптации.

Ключевые слова: лингводидактическая среда, естественная среда, искусственная среда, ИКТ, принципы обучения, иностранный язык, процесс обучения, текст, языковое окружение.

Л.А. Дунаева предлагает оценивать внешнюю среду с дидактической точки зрения, открывать в объектах внешней среды их педагогические возможности, отбирать объекты и реалии среды, компоновать их в зависимости от целей обучения [4]. Преподаватель, взаимодействуя с созданной им лингводидактической средой, именно через ее ресурсы и инструменты находится в опосредованном контакте с учащимся, который, в свою очередь, обогащает ее результатами своей практической деятельности.

Основными компонентами лингводидактической языковой среды мы рассматриваем материальные реалии из страны языковой метрополии; аудиовизуальный ряд; речевой ситуативный ряд; текст (печатный, звучащий, электронный), но основным компонентом лингводидактической языковой среды, направленной на 
обучение речевому общению, является речевой ситуативный ряд. Мы различаем учебные речевые ситуации и естественные речевые ситуации. Речевая ситуация это специфически установленные условия и отношения, которые в целях коммуникации вынуждают учащихся и дают возможность им реализовывать речевой материал в его фонетически и грамматически правильном выражении [8, с. 21]. Мы рассматриваем учебную речевую ситуацию как некую парадигму обстоятельств и условий, которые преподаватель предлагает учащимся с целью коммуникации.

Естественная языковая среда в отличие от искусственной языковой среды значительно увеличивает круг речевых ситуаций, предоставляя цепи аутентичных речевых ситуаций, которые демонстрируют полную и объективную картину финального уровня владения речевыми и языковыми навыками и умениями в изучаемом языке.

Речевые ситуации, согласно Е.М. Верещагину и В.Г. Костомарову, делятся на стандартные и вариабельные [2, с. 20-64, 65-79]. Оба этих типа речевых ситуаций существуют в реальной коммуникации в языковой среде, но преобладают вариабельные. В стандартных речевых ситуациях вербальное и невербальное поведение жестко регламентируется, в связи с их легко можно воспроизвести в условиях учебной аудитории, применяя наглядные пособия. Однако наличие естественной языковой среды дает возможность значительно раздвинуть рамки учебной работы и сделать усвоение языкового и поведенческого узуса более прочным. Аутентичная стандартная ситуация отличается от учебной ситуации актуальностью, наглядностью, и только в языковой среде есть возможность в естественных условиях осуществить методическую цепочку «наблюдение - отработка - практика - самоконтроль и самокоррекция» (вспомним здесь идею А.А. Леонтьева о ее диагностической функции).

Значительный интерес представляет национальное коммуникативное поведение, которое определяется как совокупность норм и традиций общения народа, определенной лингвокультурной общности [7; 10]. И если главной задачей учебного процесса в лингводидактической языковой среде является обучение речевому общению, то, обучая иностранному языку на основе ситуативного принципа, важно фиксировать внимание на коммуникативном поведении носителей языка и постоянно его комментировать. С коммуникативным поведением вплотную связан национальный социокультурный стереотип речевого общения. Термин «стереотип» подразумевает нечто устоявшееся и привычное, подвергающееся влиянию времени, но всё же функционирующее в общении носителей языка достаточно длительное время [8, с. 27].
Ю.Е. Прохоров предлагает четыре модели межкультурных языковых контактов: 1) соприкосновение, 2) приобщение, 3) проникновение, 4) взаимодействие [11, с. 104-112].

Таким образом, речевые ситуации, коммуникативное поведение, социокультурные стереотипы речевого поведения, межкультурные языковые контакты позволяют номинировать рассматриваемый компонент лингводидактичекой языковой среды как ситуативный ряд.

Еще одним важнейшим компонентом лингводидактической языковой среды является текст (печатный, звучащий и электронный). Интернет предоставляет широчайшие возможности для контакта с иноязычным текстом во всех его жанровых разновидностях.

Ю.Е. Прохоров в книге «Действительность. Текст. Дискурс» демонстрирует содержательное наполнение текста как единицы языка. По его мнению, текст относится к явлению языковой и экстралингвистической действительности, представляющей собой сложный феномен: это и средство коммуникации, и способ хранения и передачи информации, отражение психологической жизни индивида, продукт определенной исторической эпохи, и форма существования культуры, а также отражение определенной национальной культуры, традиций [9, с. 46-53].

В настоящее время благодаря возможности знакомиться с сайтами иноязычных журналов, газет, радио и телевидения спектр функционирования текста значительно расширяется. Гипертекст является особым типом текста, источником информации для межкультурной коммуникации в электронно-виртуальной реальности и возможности ведения дискурса, средство доступа к образовательным ресурсам, где реализуется язык и где благодаря тексту можно эффективно решать вопросы формирования языковой и коммуникативной компетенции студентов [1, с. 36]. В гипертекстовой мультимедийной среде обучения учащиеся по заданию преподавателя или самостоятельно ищут и отбирают нужную информацию для обучения и для общения в виртуальной сети, приобщаются к национальному менталитету, формируют языковую картину мира. Работа с национальной и языковой локализацией мультимедийного гипертекстового пространства дает возможность индивидуализировать процесс обучения, сделать его более интересным и увлекательным, подготовить учащегося к реальному контакту с иноязычной культурой, пополнить его словарный запас, стимулировать его активность и мотивацию, побудить к установлению контактов с носителями языка в виртуальной сети.

Использование в процессе обучения ИКТ способствует интеллектуализации учебной деятельности, из- 
менению структуры и содержания образования. Это приводит к расширению границ представлений о частнодидактических принципах.

Обучение речевому общению реализуется с помощью таких частнодидактических принципов, как [3, c. 95-114]:

Принцип межкультурного взаимодействия. Межкультурное взаимодействие в гипертекстовом пространстве способствует формированию межкультурной компетенции учащихся, овладевать знаниями о языковой картине мира носителя изучаемого языка, приобретать фоновые знания.

Принцип устного опережения. В процессе обучения иноязычному речевому общению в виртуальной среде первое место занимает обучение чтению и письму в опосредованных компьютерах формах. Чтение текстов с использованием текстовых редакторов приобретает формы синтетического вида речевой деятельности. Письменное комментирование текста или его фрагмента, выделение важной информации, удаление ненужной информации осуществляется параллельно с процессом чтения, приводят к созданию своего текста. Ученые подчеркивают, что письменное общение в чатах, форумах приближается к устным формам речи, объединяя в себе специфику быстрого чтения и устно-письменные формы речи.

Принцип функциональности основывается на функционально-смысловом подходе. Благодаря информационно-коммуникативным технологиям, существенно увеличиваются ситуации общения человека. Таким образом, в процессе обучения иностранному языку встает задача формирования и развития вторичной языковой личности. Учащиеся должны уметь самостоятельно приобретать знания, осуществлять поиск, отбор и анализ информации. Содержание обучения иностранному языку модифицируется и расширяется. Единицей обучения является гипертекст.

Принцип коммуникативности. Обучение в виртуальной среде с использованием информационно-коммуникативных технологий, связана с реальной деятельностью общения. Коммуникативное обучение всегда предполагало решение задач с целью вовлечения учащихся в общение на иностранном языке. В виртуальной среде учащийся является участником реального общения. Мотивированность их устных и письменных высказываний непосредственно связана с их внутренней потребностью. В виртуальной среде учащиеся создают тексты, которые затем они смогу использовать в различных ситуациях общения.

Принцип вариативности состоит в предоставлении учащемуся свободы выбора траекторий обучения, необходимых средств и инструментов деятельности. Данный принцип направлен не только на учащегося, но и на преподавателя, предоставляя ему свободу в отборе инструментов педагогического воздействия, способов контроля за результатами учебного процесса.

Принцип дидактической интегрированности. Данный принцип подразумевает определенный подбор средств информационно-коммуникативных технологий для решения дидактических задач. Этот принцип приобретает особое значение в настоящее время, когда любые среды на основе информационно-коммуникативных технологий могут взаимодействовать между собой. В процессе конструирования среды обучения необходимо их тщательное изучение с точки зрения методики, выделение информационных объектов, обладающих дидактической ценностью, определение их роли, места в системе обучения.

Принцип интерактивности в виртуальном обучении осуществляется в процессе взаимодействия учащихся со средствами информационно-коммуникативных технологий. Информационные технологии дают возможность не только организовать процесс взаимодействия учащегося с учебным материалом и с преподавателем, но и обеспечить общение средствами изучаемого языка с его носителями.

Такая среда, благодаря расширению межличностных отношений, приобретает более глубокое содержание как педагогический инструмент. Обучение проходит в форме сотрудничества между учащемся и преподавателем, выполняющего роль консультанта в процессе осознанного, самостоятельного поиска учащимся новых знаний и способов решения проблемных ситуаций.

Необходимо подчеркнуть, что в настоящее время перспективными являются те дидактические среды, которые внедряют информационно-коммуникативные технологии. Обучение в таких средах предполагает создание условий для активной речевой деятельности.

Принцип открытости среды подразумевает расширение среды в зависимости от интересов, мотивов, образовательных потребностей учащегося. Данный принцип имеет отношение и к учебному процессу по овладению иностранным языком, осуществляемому в лингводидактической среде с внедрением телекоммуникаций. Ученые отмечают, что любая информационная среда открыта для педагогического сообщества и для сообщества изучающих тот или иной иностранный язык, имеющих возможность работать с ресурсами Интернет, открыта для комментариев, конструктивной критики, сотрудничества и непосредственного использования в целях обучения [5]. 
Принцип челесообразности применения ИКТ. При создании среды обучения первостепенным является включение в содержание обучения тех аспектов обучения иностранному языку, которые могут быть успешно осуществлены с помощью ИКТ. Преподаватель, применяющий ИКТ в процессе обучения, должен адаптировать методики и подходы в зависимости от конкретного курca.

Для создания мультимедийной лингводидактической среды, используются такие инструменты, как: Google Classroom, Padlet, Quizlet, LearningApps.

От преподавателя зависит определение места и роли аутентичных мультимедийных ресурсов в профессионально ориентированном обучении, отбор, методическая адаптация, придание им дидактических свойств и средовая интеграция вокруг учащихся.

С создания насыщенного языкового окружения нами были определены аутентичные мультимедийные компоненты лингводидактической среды, отобранные по таким критериям, как: краткость новостной информации, повторяемость новостной информации, доступность ресурса в стране изучения иностранного языка, мультиформатность, разножанровость. Таким образом, в среду обучения были интегрированы зарубежные радиостаниии; зарубежные телевизионные каналы; иноязычные газеты и журналы. Всё перечисленное обеспечивает погружение в языковую среду страны изучаемого языка и способствует приобретению учащимися коммуникативно-речевых билингвальных умений.

Кроме того, учитывался критерий учебной/образовательной направленности, на основании которого в состав среды вошли сайты иноязычных обучающих программ с аудио- и видеозаписями актуальных репортажей, снабженными упражнениями на обучение аудированию, письму и лексике с учетом уровня владения иностранным языком.

ИКТ являются неисчерпаемым источником приобретения коммуникативно-речевых билингвальных умений. Они демонстрируют иностранный язык в реальной, повседневной жизни общества, противопоставляют его учебному языку - безукоризненному, готовому к выполнению дидактических задач.

Основную роль в использовании текстов средств массовой информации в процессе обучения иностранному языку принадлежит сайтам зарубежных газет и журналов. Они имеют ряд преимуществ по сравнению с аутентичными текстами телевидения и радио при обучении иностранному языку в искусственной языковой среде. Во-первых, подача информации на сайте газеты или журнала создает условия для обзорного знакомства с информацией, для определения приоритетов в чтении. Гипертекст в иноязычном виртуальном пространстве, благодаря своей статичности, дает возможность многократного прочтения информации для ее дополнительного осмысления, для работы над языковыми явлениями в тексте. B podcast можно читать, слушать ранее записанные информационные, публицистические, художественные и развлекательные передачи. Гипертекст дает возможность учащемуся регулировать процесс восприятия в зависимости от сформированных навыков чтения и темпа чтения. Визуальное восприятие гипертекста помогает лучшему запоминанию языковых средств.

Организация учебного процесса на основе мультимедийной модели активного обучения иностранному языку позволит: поддержать метамотивацию обучаемых к процессу обучения вообще и мотивацию к изучению иностранного языка в частности; сформировать новые знания в области языкового общения, используя когнитивные процессы для анализа и синтеза полученной информации, междисциплинарные связи и жизненный опыт учащихся [6, с. 343-344].

Подводя итог необходимо сказать, что средства ИКТ (прежде всего телевидение, радиостанции, сайты зарубежных газет, журналов телевидения и радиостанций) являются неисчерпаемым источником для приобретения коммуникативно-речевых билингвальных умений. ИКТ способствуют решению следующих дидактических: 1) формирование и совершенствование навыков чтения; 2) формирование и совершенствование навыков аудирования; 3) формирование и совершенствование навыков и умений монологической и диалогической речи; 4) обогащение лексического запаса; 5) приобретение страноведческих и культуроведческих знаний; 6) формирование культуры общения; 7) формирование устойчивой мотивации познавательной деятельности; 8) формирование межкультурной компетенции; 9) использование учебного иноязычного виртуального пространства способствует изучению иностранного языка в естественной языковой среде; 10) в интерактивной форме выполнять упражнения на лексику и на грамматику; 11) интерактивно работать над иностранным языком, в зависимости от уровня владения им.

Эффективное использование возможностей среды, способствует вовлечению учащихся в мир аутентичных ситуаций, результативно сказывается на усвоении изучаемого языка. Все вышеизложенные принципы способствуют конструированию эффективной среды обучения на основе внедрения информационно-коммуникативных технологий. 


\section{ЛИТЕРАТУРА}

1. Болдова Т.А. Обучение студентов старших курсов иностранному языку на основе использования электронных гипертекстов (немецкий язык, языковой вуз): диссертация ... доктора педагогических наук: 13.00.02. М., 2014. 490 с.

2. Верещагин Е.М., Костомаров В.Г. В поисках новых путей развития лингвострановедения: концепция рече-поведенческих тактик. М., 1999.84 с.

3. Вишняков С.А., Дунаева Л.А. Иноязычная вербальная коммуникация: преподавание, изучение освоение в контексте теории средового подхода. Монография. М.: Флинта-Наука, 2017. 167 с.

4. Дунаева Л.А. Дидактическая интегрированная информационная среда для иностранных учащихся гуманитарных специальностей, изучающих русский язык как средство научного общения. Дис. ... д-ра пед. наук. М., 2006.

5. Зайцева Е.Н. Информационно-обучающая среда как средство развития самостоятельной работы студентов при обучении иностранному языку: дисс. ... канд. пед. наук. М., 2003.

6. Кащук С.М. Стратегия интеграции мультимедиа технологий в систему языкового образования (на примере обучения французскому языку): диссертация ... доктора педагогических наук: 13.00.02. М., 2014. 427 с.

7. Лемяскина Н.А., Стернин М.А. Коммуникативное поведение младшего школьника. Воронеж, 2000. 195 с.

8. Орехова И.А. Обучающий потенциал русской среды в формировании лингвокультурологической компетенции иностранных учащихся. Дис. ... д-ра пед. наук. М., 2004.

9. Прохоров Ю.Е. Действительность. Текст. Дискурс. М., 2004. 224 с.

10. Прохоров Ю.Е., Стернин И.А. Русское коммуникативное поведение. М., 2007. 328 с.

11. Прохоров Ю.С. Национальные социокультурные стереотипы речевого общения и их роль в обучении русскому языку иностранцев. М.: Педагогика-пресс, 1997.216 C.

(c) Бурина Елена Владимировна (helenabourina@yandex.ru).

Журнал «Современная наука: актуальные проблемы теории и практики»

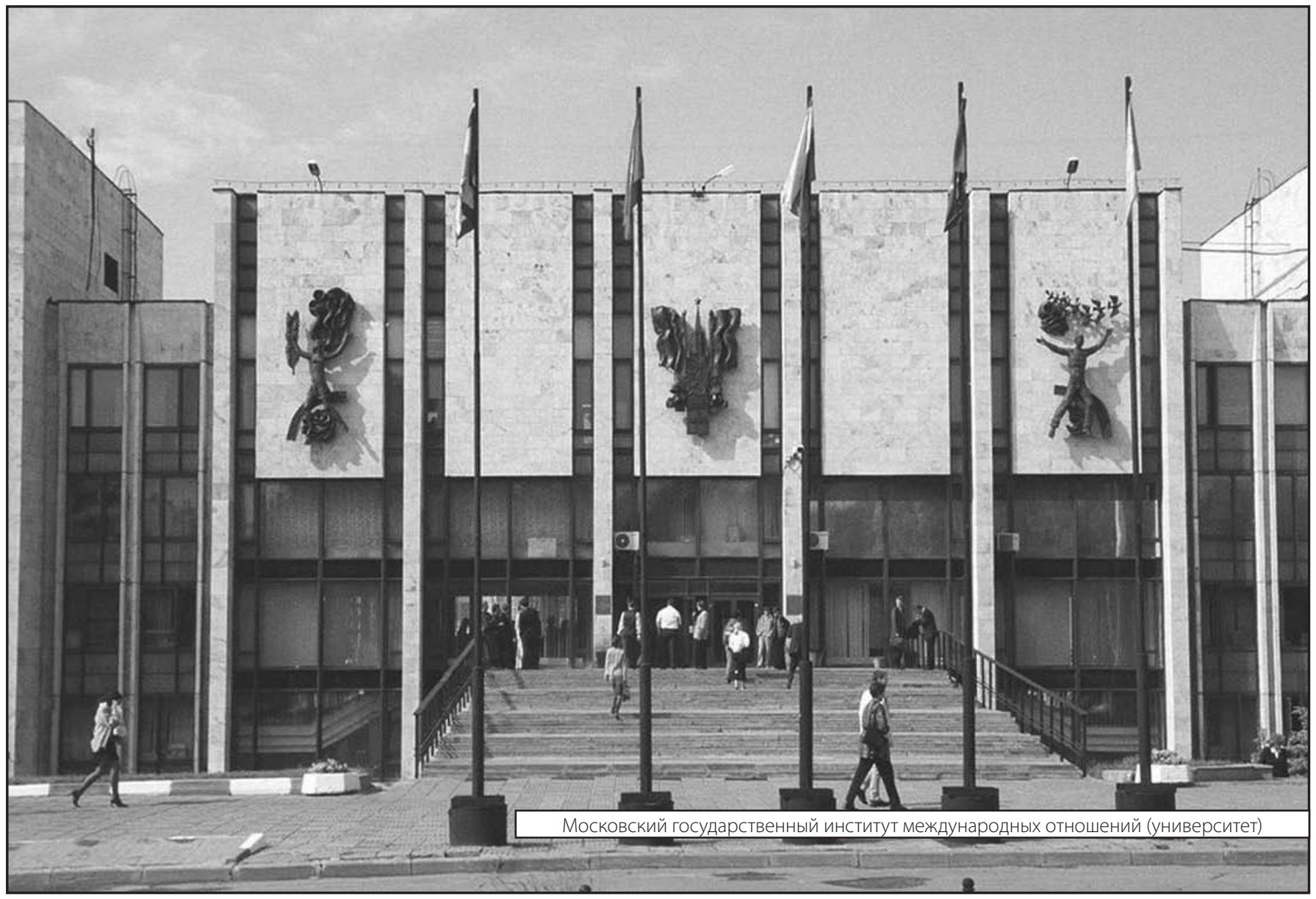

